Jurnal Perikanan (2021) Volume 11. No. 2 : 178-185

DOI : https://doi.org/10.29303/jp.v11i2.253

\title{
PEMANFAATAN Pseudomonas putida SEBAGAI BIOREMEDIATOR LIMBAH IKAN KOI (Cyprinus carpio L.) PADA SISTEM AKUAPONIK
}

\section{UTILIZATION OF Pseudomonas putida AS A BIOREMEDIATOR OF WASTE KOI FISH (Cyprinus carpio L.) IN AQUAPONIC SYSTEMS}

\author{
Maharrani Rahayu Pratiwi $^{1 *}$, Sri Andayani ${ }^{1)}$, M. Firdaus ${ }^{1)}$ \\ 1) Program Study Budidaya Perairan, Universitas Brawijaya \\ jalan Veteran no 1 Malang \\ *)alamat korespondensi: maharranirahayup@gmail.com
}

\begin{abstract}
Abstrak
Indonesia merupakan salah satu sentra perikanan yang memberikan kontribusi signifikan terhadap produksi ikan secara internasional. Jumlah produksi ikan tersebut tak lepas dari kegiatan budidaya baik ikan konsumsi maupun ikan hias. Salah satu ikan hias yang dikembangkan dan menjadi komoditas utama untuk diperdagangkan ialah ikan koi, bahkan menjadi komoditas andalan di beberapa daerah diantaranya Sukabumi, Cianjur, dan Blitar (Kursini, 2015). Oleh karena itu perlu dilakukan penelitian mengenai pengaruh perbedaan pemberian Pseudomonas putida terhadap kelangsunga hidup ikan Koi. Metode yang digunakan dalam penelitian ini adalah metode eksperimen, yang kemudian masing-masing diulang 3 kali. Pada penelitian ini menggunakan metode Rancangan Acak Lengkap (RAL) dengan pola faktorial. Faktor pertama adalah penambahan bakteri dalam sistem budidaya ikan, dimana ikan diberikan 20 ekor perakuarium. Hasil uji pengaruh pemberian Pseudomonas putida pada penelitian ini menghasilkan bahwa pertambahan bobot ikan koi pada sistem akuaponik yang lebih tinggi yaitu $4,8 \pm 0,12 \%$, Sedangkan pada budidaya ikan koi yang terendah didapatkan hasil yaitu $3,6 \pm 0,12 \%$. sedangakan pada $\mathrm{pH}$ rata-rata $\mathrm{pH}$ ikan koi pada sistem akuaponik yang lebih tinggi yaitu 8,36 Sedangkan pada budidaya ikan koi yang terendah didapatkan hasil yaitu 8,25 dan Fosfat bahwa rata-rata Fosfat ikan koi pada sistem akuaponik yang lebih tinggi yaitu 2,58 $\mathrm{mg} / \mathrm{l}$, Sedangkan pada budidaya ikan koi yang terendah didapatkan hasil yaitu 1,11 mg/l membuat turun dan membuat kualitas air membaik.
\end{abstract}

Kata Kunci : Bioremediasi, SGR, Pseudomonas putida, Ikan Koi

\begin{abstract}
Indonesia is a fishery center that contributes significantly to international fish production. The amount of fish production can not be separated from the cultivation of both consumption fish and ornamental fish. One of the ornamental fish that has been developed and has become the main commodity for trading is koi fish, and it has even become a mainstay commodity in several areas including Sukabumi, Cianjur, and Blitar (Kursini, 2015). Therefore, it is necessary to do research on the effect of different administration of Pseudomonas putida on the survival of Koi fish. The method used in this research is the experimental method, which is then repeated 3 times each. In this study used the Complete RandomIzed Design (RAL) method with factorial patterns.
\end{abstract}


The first factor is the addition of bacteria in the fish farming system, where the fish are given 20 silveruariums. The results of the test of the effect of giving Pseudomonas putida in this study resulted that the higher koi fish weight gain in the aquaponics system was $4.8 \pm 0.12 \%$, while the lowest koi fish culture was $3.6 \pm 0.12 \%$. while the average $\mathrm{pH}$ of koi fish in aquaponic systems is higher, namely 8.36. Meanwhile, in the lowest koi fish culture, the results are 8.25 and Phosphate that the average phosphate of koi fish in aquaponic systems is higher, which is 2, 58 $\mathrm{mg} / \mathrm{l}$, while the lowest koi fish culture yielded $1.11 \mathrm{mg} / \mathrm{l}$ which decreased and improved water quality.

Keywords: Bioremediation, SGR, Pseudomonas putida, Koi Fish

\section{PENDAHULUAN}

Indonesia merupakan salah satu sentra perikanan yang memberikan kontribusi signifikan terhadap produksi ikan secara internasional. Jumlah produksi ikan tersebut tak lepas dari kegiatan budidaya baik ikan konsumsi maupun ikan hias. Salah satu ikan hias yang dikembangkan dan menjadi komoditas utama untuk diperdagangkan ialah ikan koi, bahkan menjadi komoditas andalan di beberapa daerah diantaranya Sukabumi, Cianjur, dan Blitar (Kursini, 2015).

Air yang kaya nutrisi dari wadah pemeliharaan akan disalurkan menuju tanaman, kemudian dimanfaatkan sebagai hara (Zidni, 2013). Seiring dengan meningkatnya kegiatan budidaya perikanan, dampak negatif terhadap lingkungan juga muncul, salah satunya yaitu meningkatnya akumulasi limbah budidaya. Akumulasi limbah budidaya berasal dari hasil sisa metabolisme ikan dan sisa pakan yang terlarut di dalam air yang bersifat toksik bagi kelangsungan hidup ikan. Menurut Ghaly et al. (2004), kegiatan budidaya menghasilkan bahan organik dan nutrien (nitrogen, fosfor dan unsur-unsur lainnya) dalam jumlah besar yang memerlukan pengolahan dan atau pembuangan. Bahan organik, nitrogen dan fosfor dimanfaatkan oleh ikan sebagai indikator utama dalam efisiensi penggunaan pakan dan sering kali parameter tersebut juga digunakan untuk mengukur dampak lingkungan dari limbah budidaya (Van Rijn 2012).
Salah satu bakteri yang banyak digunakan sebagai biomaterial dalam berbagai penelitian biosorpsi adalah genus Pseudomonas seperti spesies Pseudomonas sp mampu menyerap logam krom (VI) dan kadmium (Cd), aeruginosa untuk logam tembaga $(\mathrm{Cu})$, kadmium $(\mathrm{Cd})$ dan timbal $(\mathrm{Pb})$. Pseudomonas putida, logam kadmium $(\mathrm{Cd})$, tembaga $(\mathrm{Cu})$, timbal $(\mathrm{Pb})$ dan seng (Zn). Pseudomonas sp, logam krom (VI) dan kadmium (Cd). Pseudomonas stutzeri, logam tembaga $(\mathrm{Cu})$. Kondisi proses biosorpsi, $\mathrm{pH}$ mendekati netral (4-7) dan waktu kontak mulai 1 jam hingga 24 jam (Vijayaraghavan et. al., 2008).

Bakteri Pseudomonas sendiri memiliki karakteristik seperti, gram negatif, berbentuk batang (rods) atau kokus (coccus), aerob obligat, motil mempunyai flagel polar. Bakteri ini, oksidase positif, katalase positif, nonfermenter dan tumbuh dengan baik pada suhu $4^{\circ} \mathrm{C}$ atau dibawah $43^{\circ} \mathrm{C}$. Pseudomonas banyak ditemukan pada tanah, tanaman dan air. Dan untuk tujuan pada penelitian ini adalah memperoleh efektivitas bioremidiator budidaya ikan koi dengan pemberian Pseudomonas putida.

\section{METODE PENELITIAN}

Masalah pada penelitian ini adalah bagaimana efektivitas bioremidiator budidaya ikan koi dengan pemberian Pseudomonas putida. Pada penelitian ini menggunakan metode Rancangan Acak Lengkap (RAL) dengan pola faktorial. Faktor pertama adalah penambahan bakteri 
dalam sistem budidaya ikan, dimana ikan diberikan 20 ekor perakuarium.

\section{Persiapan Alat dan bahan pemeliharaan}

Wadah yang digunakan dalam penelitian ini meliputi 18 akuarium berukuran 60 × 40 × $40 \mathrm{~cm} 3,18$ nampan, Styrofoam, alumunium foil, pot berdiameter $16 \mathrm{~cm}$, pipa paralon ukuran AW 1", pompa air celup, keran buka tutup, termometer, water heater, serta peralatan lainnya untuk pengujian kualitas air. Bahan yang digunakan dalam penelitian ini adalah bibit selada yang berumur dua minggu dengan tinggi rata-rata $4-5 \mathrm{~cm}$, ikan koi (Cyprinus carpio L.) dengan panjang total $5-6 \mathrm{~cm}$, Pseudomonas putida, nutrisi tambahan $\mathrm{AB}$ mix untuk tanaman, media tanam selada romaine (rockwool), pakan ikan, air media pemeliharaan dan bahan-bahan lainnya untuk pengujian kualitas air.

\section{Persiapan Biota}

Pada Sistem Akuaponik Ikan koi (Cyprinus carpio L.) berukuran $5-6 \mathrm{~cm}$ ditebar dengan padat tebar 20 ekor per akuarium. Menurut Saparinto (2018), penebaran ikan koi dapat dilakukan dengan padat tebar 200-400 ekor/ $\mathrm{m}^{3}$.

Sebelum ditebar, ikan diaklimatisasi selama satu minggu agar terjadi akumulasi nutrien untuk menyediakan nutrisi bagi tanaman. Selama 60 hari ikan dipelihara dan diberi pakan komersil sebanyak 3\% dari bobot rata-rata ikan (Saparinto, et al. 2015) dengan frekuensi pemberian pakan tiga kali sehari. Pengukuran panjang dan bobot dilakukan setiap minggu.

\section{Pemberian Pakan}

Pemberian pakan ikan koi dilakukan pada masing-masing bak perlakuan sebanyak tiga kali sehari yaitu pada pukul 08.00, 12.00 dan 16.00. Pakan yang diberikan sejumlah 3\%-5\%dari biomassa ikan (Purnomo, 2012).

\section{Pemberian Bakteri}

Inokulan Pseudomonas putida diperoleh dari Fakultas Kedokteran. Sebelum ditanam, dilakukan pengenceran bakteri terlebih dahulu. Pemberian Pseudomonas putida diberikan dengan dosis $1.5 \mathrm{~mL} /$ Liter air setiap satu minggu sekali dengan kepadatan $10^{5}$.

\section{Pengambilan Sampel Bakteri pada Media Akuaponik}

Pengambilan sampel Pseudomonas putida dari sistem akuaponik. dilakukan sebanyak 2 kali selama pemeliharaan yaitu awal pemeliharaan dan akhir pemeliharaan. Sampel diuji di Laboratorium Parasit dan Penyakit Ikan Fakultas Perikanan Universitas Brawijaya.

\section{Sterilisasi}

Sterilisasi merupakan upaya pemusnahan bakteri-bakteri yang tidak diinginkan. Menurut Kismiyati, (2009), metode yang digunakan untuk mensterilkan media adalah menggunakan autoclave, dengan menggunakan uap bertekanan untuk menaikkan suhu media yang disterilkan sampai suatu taraf yang mematikan semua bentuk kehidupan. Sterilisasi media dengan autoclave menggunakan suhu $121{ }^{\circ} \mathrm{C}$ pada tekanan uap 1 atm selama 15 - 20 menit. Pada penelitian ini sebelum dilakukan sterilisasi dengan autoclave, alat dicuci terlebih dahulu untuk menghilangkan sisa kotoran dan debu.

\section{Pembuatan Larutan Na Fisiologis}

Langkah yang harus dilakukan untuk membuat larutan $\mathrm{Na}$ fisiologis adalah dengan cara menimbang $0,9 \mathrm{~g} \mathrm{NaCl}$ yang kemudian dilarutkan pada $100 \mathrm{~mL}$ akuades yang sudah dimasukkan ke dalam Erlenmeyer. Selanjutnya dihomogenkan dengan spatula dan didapatkan $\mathrm{Na}$ fisiologis dengan konsentrasi 0,9\%. Jumlah total $\mathrm{NaCl}$ 
yang ditimbang dan akuades sebagai pelarut disesuaikan dengan banyaknya pengenceran. Selanjutnya diambil $9 \mathrm{~mL} \mathrm{Na}$ fisiologis dan dimasukkan ke dalam tabung reaksi. Setelah itu tabung reaksi dibungkus dengan kapas dan alumunium foil untuk disterilisasi. Menurut Yuswantina et al. (2012), larutan fisiologis $(\mathrm{NaCl} 0,9 \%)$ dibuat dengan cara 31 terlebih dahulu menimbang sejumlah 0,9 $\mathrm{g} \mathrm{NaCl}$ kemudian dilarutkan dalam akuades sampai mencapai volume $100 \mathrm{~mL}$.

\section{Pembuatan Media Tumbuh Bakteri}

Media tumbuh bakteri yang digunakan pada penelitian ini adalah media TSA. Langkah yang dilakukan untuk membuat media tumbuh bakteri adalah terlebih dahulu ditimbang $10 \mathrm{~g}$ TSA lalu dicampurkan dengan akuades sebanyak $250 \mathrm{~mL}$. Selanjutnya dihomogenkan dengan spatula dan dibungkus dengan kapas dan alumunium foil untuk selanjutnya dilakukan sterilisasi dengan autoclave selama 15-20 menit. Hal ini dimaksudkan untuk mencegah terjadinya kontaminan yang masuk ke dalam media hidup bakteri. Setelah diperoleh media yang telah dipanaskan dan steril, media tersebut dibagi ke dalam 12 cawan petri yang tersedia dimana untuk 1 cawan petri biasanya dapat diisi dengan $20 \mathrm{~mL}$ media agar (Kusuma et al., 2014).

\section{Pengenceran}

Pengenceran suspense bakteri diperlukan dalam rangka memudahkan dalam pengamatan koloni bakteri, terutama dalam kegiatan pemurnian isolat bakteri. Langkah awal yang dilakukan saat pengenceran adalah setiap tabung reaksi terlebih dahulu diisi dengan $9 \mathrm{~mL} \mathrm{Na}$ fisiologis. Selanjutnya sampel bakteri yang telah dicampur dengan akuades diambil 1 $\mathrm{mL}$ dan dimasukkan pada salah satu tabung reaksi. Tabung reaksi ini kemudian dihomogenkan dengan vortex mixer dan didapatkan pengenceran $10^{-1}$. Kemudian, dari pengenceran $10^{-1}$ ini diambil $1 \mathrm{~mL}$ menggunakan mikropipet bluetip steril kemudian dimasukkan pada tabung reaksi kedua yang berisi $9 \mathrm{~mL} \mathrm{Na}$ fisiologis dan dihomogenkan sehingga didapatkan pengenceran $10^{-2}$. Selanjutnya sampai didapatkan pengenceran sampai $10^{-8}$.

\section{Penanaman}

Bakteri yang terdapat pada sampel diinokulasi pada media dengan metode tuang. Metode tuang dilakukan dengan dengan cara menghomogenkan sampel pada pengenceran $10^{8}$ dengan vortex mixer kemudian masing masing sampel diambil 1 $\mathrm{mL}$ dengan mikropipet bluetip steril. Sampel yang telah diambil dimasukkan ke dalam cawan petri dan diberi label. Selanjutnya dituang media ke dalam cawan petri sebanyak $\pm 20 \mathrm{~mL}$ secara aseptik dan diinkubasi pada suhu $33^{\circ} \mathrm{C}$ di dalam inkubator selama $1 \times 24$ jam.Isolat bakteri menunjukkan bentuk yang berbeda-beda seperti warna dan bentuk koloni bakteri.

\section{Isolasi}

Bakteri pada media tumbuh tanaman diambil sebanyak 2 sampel dari masingmasing perlakuan berbeda. Proses isolasi atau pemisahan serta pemurnian isolat bakteri ini mengacu pada Setyati dan Subagiyo (2012), bahwa pemisahan dan pemurnian isolat bakteri dilakukan dengan metode gores (streak method). Masingmasing cawan petri pada tiap pengenceran diambil koloni-koloni bakteri yang menunjukkan morfologi dan warna yang berbeda. Selanjutnya masing-masing koloni bakteri digoreskan pada permukaan media steril yang telah disiapkan. Cawan petri tersebut diinkubasi pada suhu kamar selama 1x24 jam dan diamati laju pertumbuhannya, apakah sudah menjadi kultur murni ataukah belum. Apabila masih terdapat jenis bakteri lainnya maka dilakukan pemisahan kembali dengan metode gores sehingga didapatkan 
kultur murni pada masing-masing cawan petri. Setalah didapatkan biakan murni pada cawan petri kemudian ditumbuhkan pada agar miring untuk selanjutnya dilakukan identifikasi.

Untuk mengetahui pengaruh pemberian Pseudomonas putida dengan pemberian terhadap pertumbuhan dan kelulushidupan pada ikan koi. Data pertumbuhan, dan pengkuran kualitas air yang diperoleh dari hasil penelitian dianalisis menggunakan analisis sidik ragam (ANOVA) pada taraf kepercayaan $95 \%$.

\section{HASIL}

\section{Laju Pertumbuhan Spesifik}

Dari pengukuran Laju Pertumbuhan Spesifik (SGR) pada media budidaya ikan koi menunjukkan adanya interaksi Pseudomonas putida terhadap laju pertumbuhan spesifik, diperolah hasil perhitungan laju pertumbuhan spesifik selama penelitian diketahui bahwa rata-rata pertambahan bobot ikan koi pada sistem akuaponik yang lebih tinggi yaitu $4,8 \pm 0,12 \%$, Sedangkan pada budidaya ikan koi yang terendah didapatkan hasil yaitu $3,6 \pm 0,12 \%$ (Gambar 1).

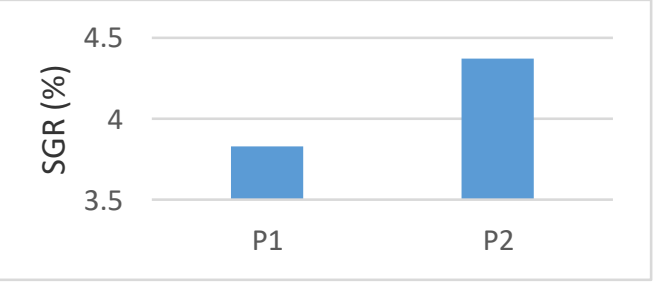

Gambar 1. Pengaruh Pseudomonas putida Terhadap SGR Ikan Koi

\section{Power of Hydrogen $(p H)$}

Dari pengukuran nilai $\mathrm{pH}$ pada media budidaya ikan koi menunjukkan adanya interaksi Pseudomonas putida terhadap $\mathrm{pH}$, maka berdasarkan hasil perhitungan Anova diperoleh hasil nilai $\mathrm{pH}$ selama penelitian diketahui bahwa rata-rata $\mathrm{pH}$ ikan koi pada sistem akuaponik yang lebih tinggi yaitu 8,36 , Sedangkan pada budidaya ikan koi yang terendah didapatkan hasil yaitu 8,25 (Gambar 2).

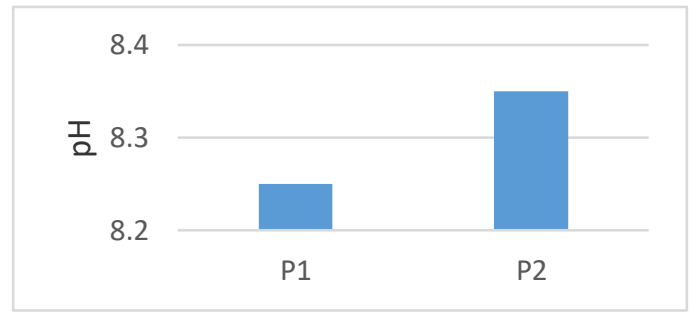

Gambar 2. Pengaruh Pseudomonas putida Terhadap $\mathrm{pH}$

\section{Fosfat}

Dari pengukuran nilai Fosfat pada media budidaya ikan koi menunjukkan Anova pada fosfat signifikan antara perlakuan dan pada interaksi, maka berdasarkan hasil perhitungan diperolah hasil perhitungan Fosfat selama penelitian diketahui bahwa rata-rata Fosfat ikan koi pada sistem akuaponik yang lebih tinggi yaitu 2,58 mg/l, Sedangkan pada budidaya ikan koi yang terendah didapatkan hasil yaitu 1,11 mg/l (Gambar 3).

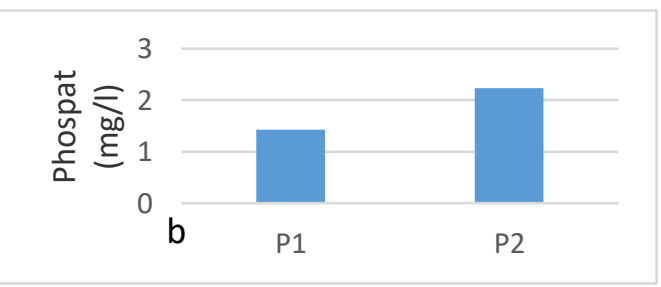

Gambar 3. Pengaruh Pseudomonas putida Terhadap Phospat

\section{PEMBAHASAN}

\section{Laju Pertumbuhan Spesifik}

Sesuai dengan pernyataan Lisna dan Insulistyowati (2015) bahwa pertumbuhan ikan meningkat karena pengaruh penambahan Pseudomonas putida dalam media pemeliharaan sehingga bakteri dapat bekerja untuk memperbaiki kualitas air juga bekerja dalam saluran pencernaan ikan. Pada perlakuan dengan penambahan Pseudomonas putida didapatkan hasil 
pertumbuhan tertinggi dibandingkan dengan perlakuan yang tanpa penambahan. Hal ini membuktikan bahwa perlakuan P2 dengan penambahan Pseudomonas putida dalam media pemeliharaan ikan dapat memperbaiki kualitas air sehingga dapat menunjang pertumbuhan ikan. Menurut Ernawati (2014), Pseudomonas putida memiliki enzim ekstraseluler yang dapat membantu pencernaan dan mampu memperbaiki kualitas air melalui penguraian dan perombakan bahan organik dalam air. Menurut Zhou and Wang (2014), penambahan Pseudomonas putida melalui air dapat berpengaruh juga pada saluran pencernaan ikan. Pseudomonas putida juga berfungsi meningkatkan daya cerna ikan terhadap pakan sehingga dapat memacu pertumbuhan ikan (Sugih, 2005). Rendahnya nilai laju pertumbuhan spesifik pada perlakuan tanpa pemberian Pseudomonas putida dibandingkan dengan perlakuan lainnya diduga karena penurunan kualitas air yang ditunjukkan oleh tingginya kadar ammonia yaitu $0,085 \pm 0,460 \mathrm{mg} / \mathrm{L}$. Hal tersebut sesuai dengan pernyataan Lisna dan Insulistyowati (2015) bahwa tingginya kadar ammonia dapat mempengaruhi pertumbuhan ikan, menyebabkan ikan stress, menurunnya nafsu makan, timbulnya penyakit dan menyebabkan kematian. Selain itu pada perlakuan kontrol tidak ditambahkan probiotik pada media pemeliharaan sehingga populasi bakteri yang dapat mengoksidasi bahan organik sedikit (Lisna dan Insulistyowati, 2015).

\section{Power of Hydrogen (pH)}

Hal ini sesuai dengan pernyataan Suprianta et al, (2020), bahwa Nilai pH tersebut masih pada tingkat yang dapat ditolerir untuk kehidupan budidaya ikan koi, tingkat $\mathrm{pH}$ yang optimal untuk proses budidaya ikan koi adalah 6,5-9,0. Terjadinya fluktuasi $\mathrm{pH}$ selama penelitian untuk setiap perlakuan diduga disebabkan oleh adanya pelepasan dan pengambilan karbondioksida (CO2) oleh organisme yang ada di dalam media pemeliharaan (Lisna dan Insulistyowati, 2015).

Menurut Pirzan \& Utojo (2013), juga menyatakan bahwa Nilai $\mathrm{pH}$ perairan dipengaruhi kegiatan fotosintesis dan pernafasan yang sedang terjadi, yaitu mulai dari nilai rendah pada waktu fajar sampai nilai tinggi pada pertengahan sore hari. Sebagaimana diketahui bahwa pada $\mathrm{pH} 6-$ 9, kehidupan biota dalam suatu perairan dapat berlangsung secara normal, baik kehidupan hewan maupun tumbuan air, karena dalam kondisi tersebut proses-proses kimia dan mikrobiologis yang menghasilkan senyawa yang berbahaya bagi kehidupan biota serta kelestarian lingkungan, tidak terjadi. Dengan demikian maka $\mathrm{pH}$ pada limbah budidaya ikan koi yang telah melalui proses bioremediasi telah memenuhi syarat untuk dilepas ke lingkungan. Dengan penambahan P. putida pada budidaya ikan koi membuat ikan koi menjadi sehat dan membuat kualitas air menjadi normal. Hal ini juga sesuai dengan Bagoes et al (2014), yang menyatakan bahwa Pengaruh $\mathrm{pH}$ terhadap pertumbuhan bakteri berkaitan dengan aktivitas enzim. Enzim diperlukan bakteri untuk mengkatalis reaksi-reaksi yang berhubungan dengan pertumbuhan bakteri. Apabila pH dalam suatu medium atau lingkungan tidak optimal maka akan mengganggu pertumbuhan ikan dan bakteri itu sendiri. Ketika $\mathrm{pH}$ menurun atau meningkat maka sifat gugus asam amino akan berubah, sehingga menyebabkan bakteri tidak dapat tumbuh optimal dan akan mempengaruhi produk metabolisme yang akan dihasilkannya (Pelczar dan Chan, 2017).

\section{Fosfat}

Didalam perairan alami, kadar fosfor hanya sedikit sekali. Jika kadar fosfor lebih dari $1 \mathrm{mg} / \mathrm{L}$ maka dapat menyebabkan 
eutrofikasi pada suatu perairan. Proses eutrofikasi dapat menyebabkan perairan memiliki konsentrasi hara yang sangat tinggi dan kandungan oksigen yang rendah. Pada kondisi seperti ini, hanya beberapa jenis tumbuhan dan hewan tertentu saja yang dapat tumbuh dan berkembang. Akibatnya, kadar nitrit dan fosfor dalam air bertambah dan mengakibatkan alga mendominasi perairan. Dengan mendominasinya alga maka akan menutup perairan dan menghalangi sinar matahari, akibatnya oksigen terlarut akan menurun sehingga mematikan ikan dan biota air lainnya. Selain itu kelebihan fosfor juga dapat menimbulkan kekurangan $\mathrm{Fe}, \mathrm{Cu}$ dan $\mathrm{Zn}$. Bila kadar fosfor dalam air sangat rendah (< 0,01 $\mathrm{mg} / \mathrm{L})$ pertumbuhan ganggang dan tanaman akan terganggu, yang dinamakan oligotrop.

Kebutuhan $\mathrm{P}$ bagi tumbuhan sangat besar tetapi sedikit lebih kecil dibawah kebutuhan akan Nitrogen. Proses penurunan kandungan Fosfor total pada unit uji terjadi karena adanya proses penyerapan Fosfor oleh akar tumbuhan, enzim fosfatase yang dihasilkan oleh berbagai mikroba dimana $\mathrm{P}$ organik diubah/dilepas menjadi Fosfat anorganik karena akar tumbuhan akan menyerap larutan fosfor dalam bentuk larutan ion fosfat anorganik (H2PO4- atau HPO42). Penguraian senyawa fosfor juga dapat terjadi akibat pembusukan bagian tumbuhan. Pengaruh tumbuhan disini sangatlah kecil, proses penurunan Fosfor total lebih dipengaruhi adanya penyerapan oleh media pasir yang merupakan sistem yang efektif dalam penyerapan kandungan Fosfor. Mekanisme penyisihan Fosfor di dalam system constructed wetland adalah penyerapan oleh tumbuhan, beberapa reaksi ikatan kimia dan pengendapan yang terjadi dalam sedimen. Pengendapan merupakan mekanisme penyisihan Fosfor yang sangat penting karena kecepatan penyisihan Fosfor melalui mekanisme ini lebih tinggi dibandingkan penyerapan oleh tumbuhan.
Pembuangan bagian tumbuhan merupakan bagian yang penting dalam menyisihkan Fosfor melalui cara kimia (Jenie dan Rahayu 1999).

Bila kadar Fosfor pada air alam sangat rendah $(<0,01 \mathrm{mg} / \mathrm{L})$, pertumbuhan tanaman dan ganggang akan terhalang. Keadaan ini dinamakan oligotrop. Selain itu, kelebihan $\mathrm{P}$ dapat menimbulkan kekuranga $\mathrm{Fe}, \mathrm{Cu}$, dan $\mathrm{Zn}$ pada tanaman karena terbentuknya Zn Fosfor yang tidak larut (Rinsema, 1983). Sedangkan dalam ilmu kesehatan, keberadaan fosfat dalam tubuh manusia atau hewan belum ada penelitian secara lebih lanjut.

\section{KESIMPULAN}

Dapat disimpulkan bahwa perlakuan bioremediasi dengan penambahan Pseudomonas putida pada penelitian selama 60 hari yaitu menghasilkan pertambahan bobot ikan koi pada sistem akuaponik yang lebih tinggi yaitu $4,8 \pm 0,12 \%$, Sedangkan pada budidaya ikan koi yang terendah didapatkan hasil yaitu 3,6 $\pm 0,12 \%$. sedangakan pada $\mathrm{pH}$ rata-rata $\mathrm{pH}$ ikan koi pada sistem akuaponik yang lebih tinggi yaitu 8,36 Sedangkan pada budidaya ikan koi yang terendah didapatkan hasil yaitu 8,25 dan Fosfat bahwa rata-rata Fosfat ikan koi pada sistem akuaponik yang lebih tinggi yaitu 2,58 mg/l, Sedangkan pada budidaya ikan koi yang terendah didapatkan hasil yaitu $1,11 \mathrm{mg} / \mathrm{l}$ membuat turun dan membuat kualitas air membaik.

\section{DAFTAR PUSTAKA}

Agustiyani, M. dan Widiyanto, T. (2014). Penggunaan bakteri nitrifikasi untuk bioremediasi dan pengaruhnya terhadap konsentrasi amonia dan nitrit di tambak udang. Oseanologi dan Limnologi di Indonesia 32 (2): 261278. ISSN 0125-9830 
Baktiar, H. 2012. Taksonomi dan Kunci Identifikasi Ikan. Penerbit Binacipta : Bogor.

Barus, R.H. and Kurtz, L.T. (2013). Determination of total organic and available forms of phosphorus in soils. Soil Science. 59: 39-45.

Bicoic, E. Cristea, V. Patrice, N. and Grecu. I. (2014). The Effect on Biochemical Composition of Different Concentrasion Probiotic Fed To Juvenile Carp (Cyprinus carpio, L. 1758) In A Recirculating Aquaculture. Scientific Papers-Animal Science Series. University of Agricultural Sciences and Veterinary Medicine Iasi. 63.

Rukmana, Dewi. (2013). Potensi Bakteri Pseudomonas pseudomallie Sebagai Biosorben Logam Berat Timbal $(\mathrm{Pb})$. Skripsi. UIN Maulana Malik Ibrahim Malang.

Setyani, M. L., Utami, dan D. Suryani. (2012). pengaruh variasi biomassa Pistia stratiotes L. Terhadap penurunan kadar BOD, COD, dan TSS limbah cair tahu di dusun klero sleman yogyakarta. KES MES, 4 (1), 1-16.

Tiana, I. Sutrisno. Yuliati, P. dan Supriyadi, H. (2014). Studi Pengaruh Suhu Air Terhadap Aktivitas Bakteri btoremedtast (N Ttromonas Dan $\mathrm{N}$ Ttrobacter) Pada Pemeliharaan Benih Ikan Patin Siam (Pangasius hypopthalmus). Jurnal Perikanan Indonesi, 11(7).

Todar. (2012). Mikrobiologi Industrsi. Yogyakarta: AndiOffset.

Twarososka,Y., H. Uchisawa, H. matsue, F. Narumi, J. Sasaki, and K.L. Iahida. (2010). An investigation of the antitumour peptidoglycan fraction from the squid ink. Biol. Pharm. Bull, 17(6), 864-851.

Van Rijn. (2012). A bacteriocin ofstrain Pediococcus sp. ISK-1 isolated from human feces. J. Bioscience, Biotechnologyand Biochemistry, 61(6), 1049-1051.

Wahwaklin, MJA., and V.L. Masuda. 2015. Toxins from marine invertebrates. In: "Marine toxin (Origin, Structure and molecular Pharmacology") (S.Hall and G.Strichartz eds.,) American chemical society, Washington DC, pp. 113- 332. Wahyuningsih.2015 Pengolahan Limbah Nitrogen dari Kegiatan Budidaya Ikan Nila (Oreochromis niloticus) Pada Sistem Akuaponik. Tesis. Institut Pertanian Bogor. Bogor. 